\title{
Study on Sustainable Development of Rural Revitalization Based on Slow Village Concept
}

\author{
Ruipeng Zhang ${ }^{1, *}$, Junwei Huo ${ }^{1}$, Changquan $\mathrm{Su}^{1}$, Yingqiang $\mathrm{Xu}^{1}$, Yiyao Zhong ${ }^{1}$, and Xin Meng ${ }^{1}$ \\ ${ }^{1}$ College of Architecture and Art, Hefei University of Technology, Hefei, China
}

\begin{abstract}
The slow village is the focus of rural development. Under the drive of the slow village, the village will achieve comprehensive economic, social and cultural revitalization and become a sustainable rural development structure in the new era. Based on the concept of "slow village", this article combines the author's rural planning proposal of Changii Village in Fanchang County to examine whether the development idea of "slow village" can promote rural revitalization. The article analyzes and researches the three aspects of production, living and ecological space in order to explore a development model of rural revitalization based on the "slow village", and provide ideas for the revitalization and ecological sustainable development of similar villages.
\end{abstract}

\section{Introduction}

The Urban and Rural Planning Law, which came into effect on January 1, 2008, includes rural planning in the scope of adjustment, divides rural planning into town-ship planning and village planning, and provides for the formulation, implementation, modification, supervision and inspection, and legal responsibility of rural planning, providing a legal basis for the systematic study of rural planning. In April 2018, the Ministry of Natural Resources was formally established, and the nationwide "multiregulation" pilot task of more than four years was basically completed, marking the construction of The conditions are ripe for the construction of a national spatial planning system, the strengthening of use control, and the comprehensive development of national spatial planning. As an important part of the territorial spatial planning, village planning is also an important prere-quisite for the national 14th Five-Year Plan to vigorously promote the revitalization of the countryside [1].

Since 1999, when the Slow City Movement Charter was published, the Slow City movement has emerged worldwide. Since the 1990s, the rapid growth of cities has been accompanied by problems such as noise, air pollution, indifference and lack of affection between people. In 1999 , the small Italian city of Bula, with only 10,000 people, proposed a new urban model that would combine modern technology with traditional lifestyles in a modern city, so that people could not only enjoy the many conveniences of modern life, but also emphasize the importance of bringing a regular and healthy lifestyle to everyone. The current fast-paced urban life reflects the confusion and disorientation brought by the high-speed life in the context of rapid urbanization [2]. With the continuous development of the slow city model, this ecological and natural development model is gradually extended to the countryside, evolving into the "slow village" concept. This will be a kind of back to life itself, people-oriented village model. It advocates people to return to the simple and pleasant living condition of the countryside.

\section{Basic information about the study area}

Changsi Village is located in the northwest of Suncun Town, surrounded by mountains on all sides, connecting Jinling in the east, Changlong in the south, Huanghu in the west, and Digang in the north. In ancient times, the mountain on the east was called Changxingling, and at the foot of the mountain on the west, there were Langling Temple and the old residence of Cui Cong, the official of the Ming Dynasty, and Guiyangchong at the back was also called Sichong. So it was later collectively called Changsi.

The total area of the village is 6.4 square kilometers, with 8 natural villages and 11 village groups under its jurisdiction. The village has a resident population of 500 people, most of whom are over 65 years old, and most of them are located in the center of the village of Old House Base. The village is mainly planting daily vegetables and rough processing of moso bamboo, producing moso bamboo, timber, tea and rich iron ore resources. In recent years, the leading industry of Changji Village has developed into forestry and tourism, which accounts for more than $80 \%$ of the income [3].

The construction of Laoyaki central village insists on the overall goal of "ecologically pleasant village beauty, prosperous industry and people's life beauty, civilized and harmonious country style beauty", fully explores the local characteristics, and strives to create a pleasant living and happy Changji. However, to sum up, the following problems still exist in the development of Changji Village:

\footnotetext{
* Corresponding author: zhangrphfut@163.com
} 
(1) the young and strong labor force is out of town, the hollowing out of the countryside is serious; (2) the traditional industries account for a high proportion, the economic development is poor; (3) the infrastructure and public service facilities are weak, the living environment needs to be improved; (4) the rural tourism is only a simple copy of the development, the management is sloppy; (5) the depth of resource mining is not deep enough, it is difficult to drive economic development [4].

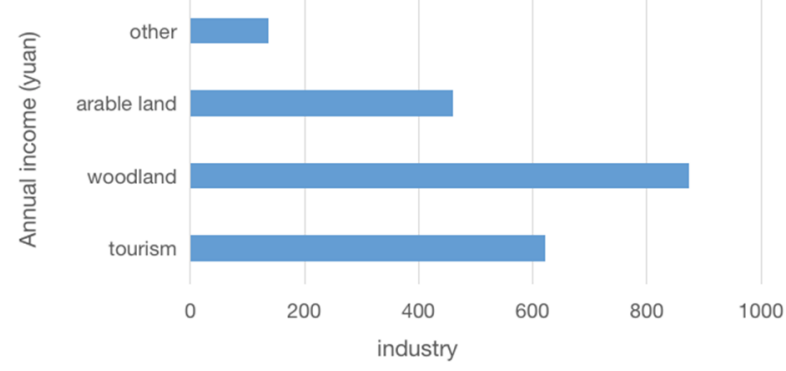

Figure 1. Per capita income of leading industries in Changsi Village.

\section{The point of convergence between the concept of slow village and Changsi village}

\subsection{The ecological background of Changsi Village is sensitive and it is surrounded by mountains and rivers}

The natural environment in Changsi Village is composed of mountains and waters. There are two reservoirs in the old house foundation, one is called Tongkou Reservoir and the other is called Wanchong Reservoir. The water is pure and green as blue. Based on the current situation of surrounding mountains and rivers, Changsi Village has the characteristics of sensitive ecological background, and one of the ideal visions that Man Village wants to create is a good ecological environment [5].

\subsection{Changsi Village is not suitable for large-scale development, and the industry is lagging behind}

Due to the sensitive nature of the ecological background in Changsi Village, the village is not suitable for largescale development, and some of the original factories are mostly shut down due to environmental pollution. The industry in Changsi Village is currently lagging behind. The Man Village emphasizes the ecological, low-carbon, and environmental protection of the industry, which is in line with the characteristics of Changsi Village.

\subsection{Changsi Village's industry lags behind, the population is lost, and the village is hollow}

Due to the lagging industry in Changsi Village, a large number of young and middle-aged laborers go out to work, which in turn leads to the loss of the village popul-ation and the village becomes hollow. The Slow Village empha- sizes slow life, returns to the simplest living conditions, and attracts foreign populations in this state, which in turn drives the development of the industry.

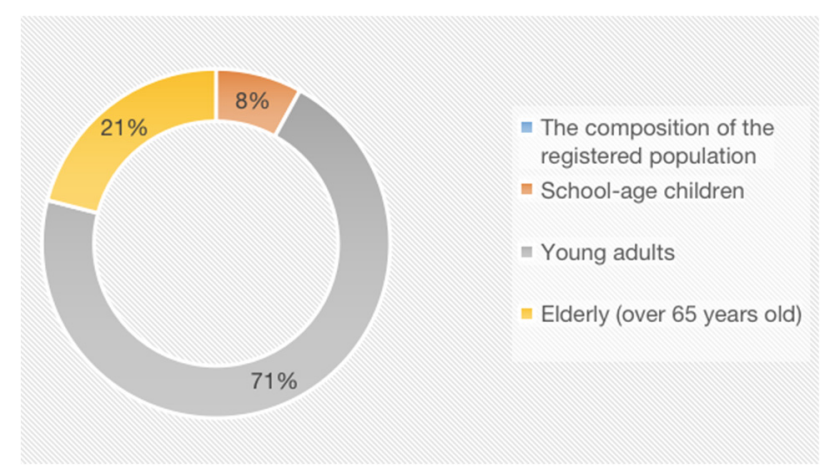

Figure 2. The composition of the registered population.

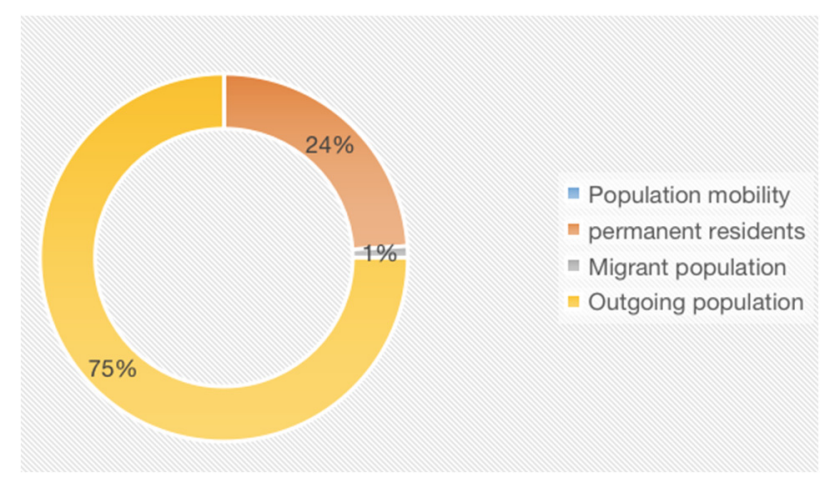

Figure 3. Population mobility.

\section{The development model of rural revitali-zation under the slow village concept}

\section{1 "Slow" promotes production and bamboo art inheritance-keeping the nature's essence and creating the industry of the slow village}

Under the concept of Slow Village, the planning concept of the production space of Changsa Village is based on the current situation of ecologically sensitive villages, respecting the law of village development under the keynote of "Slow Village", shutting down mining and polluting factories for transformation, returning to traditional ecological industries, re-understanding the potential value of traditional ecological industries, optimizing industrial quality and added value of products. On the one hand, we optimize the industrial structure, take the third industry such as bamboo culture eco-tourism, B\&B and bamboo weaving e-commerce as the core, drive the optimization of the second industry such as moso bamboo deep processing crafts and bamboo weaving skills, and promote the development of the first industry such as moso bamboo breeding and poultry breeding. On the other hand, we will create a special industry integrating moso bamboo planting, deep processing, bamboo culture display and experience, ecological tourism and leisure, and form an industrial chain from moso bamboo planting to bamboo art deep processing and then to bamboo series 
products selling [6]. The planning strategy includes the following three aspects.

\subsubsection{Improve the first production}

Firstly, enrich bamboo species and expand planting. Seek professional guidance from forestry personnel, introduce more suitable bamboo species and enrich the diversity of bamboo resources. Expand the planting area, increase the scale, and provide guarantee for the development of second and third production; on the other hand, improve the protection of bamboo resources and scientific management. Due to the short and cheap growth cycle of moso bamboo, the management of bamboo resources has always been under-appreciated. Scientific planting and management are especially important for sustainable development and tourism landscape shaping.

\subsubsection{Retreat two into three}

First of all, ecological restoration of abandoned mines and full retreat of polluting industries. The ecological restoration of the abandoned mine, the full retreat of the village's polluting industries, the transformation of the original site, combined with the bamboo handicraft industry, to create a bamboo cultural creative handicraft park and e-commerce storage space; on the other hand, the inheritance of bamboo culture, the development of collective economy. The village has a long history of bamboo art culture, but due to the loss of personnel, it is difficult to develop, create a "micro factory" to help the poor handicraft industry, provide entrepreneurial opportunities to attract the return of personnel, while establishing bamboo art deep processing industry.

\subsubsection{Upgrading of three industries}

First of all, we will develop bamboo culture and slow life ecological tourism. Create bamboo culture display experience, ecological tourism leisure tourism industry, in line with the village terrain, to create from the city to Changji, from fast to slow into the Zen forest of the secluded slow life experience, to find inner peace; on the other hand, combined with the advantages of the location of the development of bamboo art e-commerce, to enhance industrial toughness. Changji village is a short drive from the town center, and is at the junction of two cities, with convenient transportation. It is suitable for the development of e-commerce for the industry with high added value like bamboo art, which is a certain complement to the tourism industry and improves the toughness of the industry.

\section{2 "Enjoy life slowly, live poetically - find the source of the slow village, shape the life of the slow village}

Under the concept of Slow Village, the planning idea of the living space of Changji Village is to alleviate the problems caused by "fast-paced urban life" and "industrialization", so that local residents and visitors can gradually find inner peace and form a comfortable and comfortable rural lifestyle. From the aspect of villagers' life, the establishment of rural community institutions, the creation of rural community, enhance the sense of belonging of the residents; from the aspect of tourists' life, shape the slow life scene of Changji, provide slow life leisure places, enhance the sense of identity of tourists. The planning strategy includes the following two aspects.

\subsubsection{Village life}

Introduce the governance model of urban neighborhood committees, strengthen the administrative functions of villagers' committees to manage village affairs, and establish separate "neighborhood committees" to manage people's affairs. The committee will be responsible for the management of the village affairs, and will build a community of villages, each with its own duties, to reshape the local relationship. On the other hand, we need to improve medical facilities, popularize medical knowledge, enhance the resilience of villages, and build healthy villages [7].

\subsubsection{Visitor life}

Shape the slow village scene together from many aspects such as slow food, slow walking, slow living and slow touring, so that visitors can experience the slow life of the countryside and mend the traditional village life affected by the modern fast-paced life.

\section{3 "Slow" life tone, green slow village - follow the theory of two mountains, subject to the ecology of slow village}

Under the concept of slow village, the planning idea of ecological space of Changii Village is (1) ecological priority and green development; (2) establish ecological sensitive control system; (3) create ecological transportation slow system; (4) educate and popularize ecological knowledge. We will build an ecological security pattern with integrity network, establish a nature reserve system with strong protection, increase the supply of high-quality ecological products, and systematically and proactively implement region-wide ecological restora-tion. The planning strategy includes the following four aspects.

\subsubsection{Ecological priority and green development}

Adhere to the development strategy of giving priority to ecology, respect the original natural conditions and protect the existing landscape pattern of villages. To build a modernization in which people and nature coexist harmoniously, we must put the protection of urban ecological environment in a more prominent position, plan the production space, living space and ecological space of the city scientifically and reasonably, handle the relationship between urban production and living and ecological environmental protection, and improve both the 
quality of economic development and the quality of people's life.

\subsubsection{Establish an ecologically sensitive control system}

Establish an environmental access system for ecologically sensitive areas, production areas should be far away from ecologically sensitive areas, and the pace of visits from entrances to ecologically sensitive areas is from fast to slow. Based on the boundaries of various prohibited development zones, ecological sensitivity analysis, and ecological service value evaluation results, the Boolean algorithm is used to superimpose prohibited development zones, ecologically sensitive areas, and areas with high ecological service value. Comprehensively consider the needs of urban development and construction and basic farmland protection land, and areas located in prohibited development zones and ecologically sensitive areas or high ecological service value areas are designated as ecological protection red lines.

\subsubsection{Create an ecological transportation slow walking system}

Urban slow walking system is slow transportation, which means that walking, bicycle, bus and other slow travel modes are taken as the main body of urban transportation, effectively solving the problems of fast and slow traffic conflicts and difficulties in traveling for slow moving subjects. This requires the community to build a complete walking and bicycle system, create a convenient and continuous walking and bicycle network, maintain the right-of-way for walking and bicycling, and optimize street functions. In addition, we should also guide the integrated transportation mode of "public transportation+slow walking" to improve the living environment and quality of life and promote a healthy life, while meeting the growing diversified needs of residents for commuting, sports and fitness, and leisure and tourism.

\subsubsection{Education and popularization of ecological knowledge}

Create ecological education bases and nature classes to popularize ecological knowledge and raise the ecological protection awareness of local villagers as well as foreign visitors. Ecological ethics is not only an important part of ecological civilization, but also a reliance and spiritual source of ecological civilization. Ecological ethics education in schools is an inevitable requirement for the country to achieve sustainable development. Ecological ethics education is an important part of ideological and moral education and an important aspect of measuring students' basic moral quality. Therefore, it is necessary to strengthen ecological moral education, cultivate people's correct understanding of the relationship between human beings and nature, enhance their sense of morality and responsibility towards nature, develop a sense of caring for the natural environment and ecological protection, and consciously observe the corresponding moral habits.

\section{Conclusion}

Based on the concept of "slow village", this study takes Changji Village in Fanchang County as the study area and explores its rural planning scheme. In the past few decades, backward villages around the world have been in a hurry to develop their economy, and have been built in a drastic manner, which has caused various problems such as the destruction of village ecology in a thousand villages. The concept of "slow village" is a reflection of the current background of ecology first, in order to let the village development and protection in parallel. However, the development status of each village is different, and rural planning should be tailored to local conditions in order to promote rural revitalization. It is worthwhile to further explore which villages can be covered by such a concept and which types of villages are suitable for development.

\section{References}

1. Liu Y. Basic theory and methodology of rural revitalization planning in China[J]. Journal of Geography, 2020, 75(06): 1120-1133.

2. Yao S, Zhou S. Research on the common construction and sharing path of rural revitalization[J]. China Rural Economy, 2020(02): 14-29.

3. Liu Y, Zhou Y, Li Y. China's rural territorial system and rural revitalization strategy[J]. Journal of Geography, 2019, 74(12): 2511-2528.

4. Zhang C, Chen M, Shao M. From slow city to slow village-a beautiful countryside development model [J]. Rural Planning and Construction, 2014(01): 2332.

5. Su X, Wen T. Eco-agriculture and Slow Village, Slow Food, Slow Life: An Interview with Professor Wen Tiejun, Executive Director of the Institute for Advanced Studies in Sustainable Development, Renmin University of China[J]. Journal of Nanning Vocational and Technical College,2019, 24(01):101104.

6. Xia S. Talking about the understanding of "international slow village construction" [J]. Shanxi Architecture, 2020, 46(03): 15-17.

7. Gao H, Zhang J, Luo Z. Revival or Alienation ? Spatial Transformation of Rural Villages on the Edge of the Metropolis Driven by Consumer Culture - An Empirical Observation of Dashan Village in Gaochun International Slow City [J]. International Urban Planning, 2014, 29(01): 68-73. 